\title{
OBTENÇÃO, AVALIAÇÃO E RECUPERAÇÃO DE MICROPARTÍCULAS DE ALGINATO-POLOXẤMERO UTILIZANDO TÉCNICA DE EMULSÃO A/O
}

\section{OBTAINMENT, EVALUATION AND RECOVERY OF ALGINATE-POLOXAMER MICROPARTICLES USING A/O EMULSION TECHNIQUE}

\author{
KAMINSKI, Gabriel A. T. 1; FIN, Margani T. 1; NUNES, Patrícia M. P. 2; COSTA, \\ Camila K. ${ }^{3}$; MIGUEL, Marilis D. ${ }^{3}$; ZANIN, Sandra M. W. ${ }^{3}$. \\ 1 - Acadêmicos do curso de Farmácia da Universidade Federal do Paraná. \\ 2 - Mestranda em Ciências Farmacêuticas pela Universidade Federal do Paraná. \\ 3 - Docentes do curso de Farmácia da Universidade Federal do Paraná. \\ e-mail para contato: sandrazanin @ufpr.br \\ REC:05/09 AC:06/09
}

\section{RESUMO}

Torna-se cada vez mais importante reduzir doses e melhorar o desempenho dos fármacos em tratamentos, onde micropartículas tem sido uma ferramenta cada vez mais empregada. Portanto, abordamos os principais métodos gerais de obtenção de micropartículas, como também os que utilizam polímeros biodegradáveis que trazem características novas e promissoras para fármacos hidrofílicos e termossensíveis. Uma das técnicas que utilizam este tipo de polímero é a de emulsificação a/o que pode ser conduzida à temperatura ambiente e, sob aquecimento para fármacos hidrofílicos e não termossensíveis, possibilitando observar variabilidades de forma e tamanho das partículas obtidas nas duas situações.

Palavras-chave: micropartículas, biopolímeros, poloxâmero, alginato, liberação controlada

\begin{abstract}
It becomes increasingly important to reduce doses and improve the performance of drugs in treatments that is the reason why microparticles have been a valuable tool. Therefore we approach the main techniques of microparticles obtainment, as well as the biodegradable polymers microparticles with their promising features for lipophilic, hydrophilic and thermo sensible drugs. One of the techniques that uses biopolymer is the w/o emulsification which can be made at room temperature or heated for those drugs that are not thermo sensible, enabling shape and size analysis of both situations.
\end{abstract}

Keywords: microencapsulation, bioencapsulation, poloxamer, alginate, controled delivery

\section{INTRODUÇÃO}

Os procedimentos de obtenção de micropartículas têm sido utilizados há décadas com o intuito de separar incompatibilidades, melhorar estabilidade de produtos, converter líquidos em sólidos, diminuir volatilidade ou inflamabilidade de líquidos, mascarar gosto e odor e reduzir toxicidade. Também facilitam a manipulação de certas formulações através da otimização de escoamento de pós coesivos, controle de tamanho de partículas, dispersão de substâncias insolúveis em água em meio aquoso, redução ou eliminação da irritação gástrica, proteção ambiental da umidade, luz, calor e oxidação e a programação e controle da liberação de fármacos em geral tanto de forma sustentada como vetorizada (MAGILL, 1991; SILVA et al., 2003). A ciência de obtenção de micropartículas exige atenção para as dificuldades encontradas na 
aplicação de métodos para a elaboração das técnicas evitando revestimento incompleto, características de liberação não reproduzíveis e instáveis bem como elevado custo de produção (VOS et al., 2009). O O método ideal de obtenção de micropartículas deve ser simples, reprodutível, rápido e fácil de transpor à escala industrial (GIUNCHEDI e CONTE, 1995). Neste trabalho apresentamos a descrição dos principais métodos de obtenção de micropartículas.

Técnica de revestimento: no revestimento clássico há o emprego de turbinas de drageamento aquecidas, onde o fármaco de natureza sólida sofre rotação e é nebulizado ou vertido em material de revestimento. Porém, quando esta técnica é aplicada por centrifugação ocorre o lançamento do fármaco contra as massas poliméricas presentes nos orifícios da centrífuga. Este tipo de revestimento permite a obtenção de um perfil de liberação mais adequado que comprimidos revestidos, conferindo diferentes perfis de liberação controlada, porém não há uniformidade na espessura do revestimento (BAKAN, 1994; LACHMAN et al., 1986).

Fluidização: as partículas sólidas são suspensas em corrente de ar quente ascendente que forma um leito fluidizado onde são revestidas por nebulização de uma solução de polímero. Exige-se uma grande quantidade de fármaco neste caso, porém o revestimento apresenta espessura mais uniforme. Riscos de explosão com solventes orgânicos são observados (AFTABROUCHAD e DOELKER, 1992).

Nebulização: o fármaco é disperso ou dissolvido em solução orgânica ou aquosa do polímero e o sistema é nebulizado em corrente de ar quente. Após a evaporação do solvente, as micropartículas são recuperadas. Caracteriza-se como uma técnica simples e rápida que permite obter um produto final sem a necessidade de isolamento ou eliminação de resíduos de solventes porém, tem alguns inconvenientes como o uso do calor, custo do equipamento e dificuldade em obter partículas esféricas (SILVA et al., 2003).

Spray-chilling e spray-desolvation: tem seu princípio na nebulização porém, com alterações em algumas das etapas ou processos utilizados, com o intuito de eliminar alguns inconvenientes da nebulização normal (GIUNCHEDI e CONTE, 1995).

Coacervação: consiste na obtenção de micropartículas a partir de uma solução contendo uma macromolécula dispersa, de duas fases imiscíveis, uma fase de coacervado, em que a macromolécula está presente em altas concentrações e uma fase equilíbrio em que a mesma está em baixa concentração. Há dois tipos de coacervação, a simples, onde há apenas uma macromolécula e o processo é induzido por uma alteração de condições que provoquem dessolvatação da macromolécula e a complexa, onde estão presentes duas ou mais moléculas de cargas opostas, sendo este processo induzido pela criação de forças eletrostáticas entre as macromoléculas (KAS e ONER, 2000). É considerada uma técnica complexa em termos operacionais e necessita de controle minucioso das condições experimentais. Porém apresenta a grande vantagem de rendimentos elevados de encapsulação de fármacos lipossolúveis (SILVA et al., 2003).

Extrusão/solidificação: as micropartículas são obtidas por microgotas do material núcleo líquido, em solução ou fundido, injetado por seringa ou tubo fino contendo o material de revestimento ou este sendo adicionado simultaneamente. O material de revestimento é solidificado por evaporação ou difusão do solvente como também através 
de reação química (DONBROW, 1992; LACHMAN et al., 1986).

Polimerização: a polimerização do monômero ocorre in situ, é feita através de uma emulsão contendo os monômeros na fase externa, normalmente aquosa, onde estão presentes o iniciador e o tensoativo. A polimerização ocorre no interior hidrofóbico de micelas do tensoativo, presente em quantidade superior à necessária para a formação de micelas, ao qual o tensoativo e os monômeros se difundem. Produz partículas pequenas, mas geralmente contêm elevadas concentrações do monômero (ARSHADY, 1991; LACHMAN et al., 1986).

Emulsificação/Solidificação: através do preparo de uma emulsão podem-se preparar microgotículas cuja fase interna, em microgotas, é solidificada originando as micropartículas. Pode-se utilizar emulsificação direta ou indireta, com inversão de fases, reduzindo o tamanho das partículas se desejado, por forças de dispersão, quando a fase externa estiver correta (SILVA et al., 2003). A solidificação pode ser feita por diversos métodos, entre eles a secagem em fase líquida, extração do solvente, reticulação química e térmica, hot-melt e interação iônica (SILVA et al., 2003). A operação de secagem em fase líquida é conhecida como evaporação do solvente. Consiste na dispersão de uma solução orgânica do polímero contendo o fármaco dissolvido, em meio insolúvel ao polímero, seguido da evaporação do solvente (ARSHADY, 1991). Na extração do solvente o solvente do polímero é miscível no meio de suspensão, passando então do polímero para o referido meio produzindo micropartículas mais regulares, com menor variação de granulometria e menor diâmetro do que a evaporação do solvente (ARSHADY, 1991; GIUNCHEDI e CONTE, 1995). A reticulação química e térmica consiste na preparação de uma emulsão a/o com a macromolécula na fase oleosa, levando à formação de gotas que, por ação do calor em temperatura acima de $50^{\circ} \mathrm{C}$ ou por adição de um agente químico reticulador, sofrem reticulação covalente. Este método fica vetado ao encapsulamento de fármacos peptídicos pelo uso do calor e de agentes químicos para a reticulação (ARSHADY, 1990; BURGUESS e HICKEY, 1994). A técnica de hot-melt consiste de emulsificação onde se obtêm gotas fundidas do polímero que por arrefecimento transformam-se em micropartículas sólidas sem a utilização de solventes orgânicos. Fica restrito a produtos termoestáveis (AFTABROUCHAD e DOELKER, 1992).

A fim de se obter micropartículas a partir de polímeros biodegradáveis com conteúdo hidrofílico MOEBUS, SIEPMANN e BODMEIER (2009) descreveram uma técnica de obtenção de micropartículas a partir dos polímeros alginato de sódio e poloxâmero 407. Estes polímeros são formadores de hidrogel e retém uma grande fração de água em seu interior sem dissolução (PARK, SHALABY e PARK 1993).

Os polióis poloxâmeros são uma série de blocos de copolímeros intimamente relacionados de óxido de etileno (a) e propileno $(b)$ conforme a fórmula geral $\mathrm{HO}\left(\mathrm{C}_{2} \mathrm{H}_{4} \mathrm{O}\right)$ $a\left(\mathrm{C}_{3} \mathrm{H}_{6} \mathrm{O}\right) b\left(\mathrm{C}_{2} \mathrm{H}_{4} \mathrm{O}\right) a \mathrm{H}$. O poloxâmero 407 é solido a temperatura ambiente, possui índice (a) 101 e (b) 56 e peso molecular médio de 9840-14600 com 71,5 a 74,9\% de óxido de etileno. Livremente solúvel na água, etanol a 95\% e isopropanol. Praticamente sem odor ou sabor.

Estes copolímeros não iônicos são utilizados como dispersantes, emulsificantes e solubilizantes. O segmento polioxietileno é hidrofílico enquanto o segmento polioxipropileno é hidrofóbico. Possuem uso externo ou interno, considerados não 
tóxicos, não irritantes e não metabolizados no organismo. Mais recentemente têm sido usados em sistemas de liberação de fármacos. Seu EHL é de 18-23. O pH de uma solução aquosa a $2,5 \%$ p/v é de $6,0-7,4$. As soluções aquosas de poloxâmero, em geral, são estáves na presença de ácidos, álcalis e íons metálicos, contudo favorecem a contaminação fúngica (ZANIN et al. 2007; ROWE, SHESKEY e WELLER, 2003).

Em solução aquosa a concentração e" $20 \%$ e temperatura e" $4^{\circ} \mathrm{C}$ transformase de uma solução de baixa viscosidade a um gel semisólido (MOEBUS, SIEPMANN e BODMEIER, 2009; SCHMOLKA, 1972). A gelificação térmica reversa e a baixa toxicidade são propriedades que fazem do poloxâmero um material útil para sistemas de liberação controlada como formador matricial por fomação de gel in situ (JEONG, KIM E BAE, 2002). Esta propriedade permite seu uso em muitos sistemas para liberação controlada e sustentada de fármacos biologicamente ativos como peptídeos e proteínas, urease, insulina e hormônio de crescimento humano.

O poloxâmero também tem sido estudado como aditivo em sistemas de liberação sustentada para uso bucal, nasal, oftálmico e retal (ZANIN, et al., 2007; JEONG, KIM e BAE 2002). Contudo, devido à dissociação das micelas empacotadas do poloxâmero em um excesso de água, a integridade do gel não persiste por períodos prolongados de tempo. A maioria das formulações mostra cinética de liberação sustentada somente por horas, como também, a maioria dos sistemas descritos são líquidos injetáveis a baixa temperatura. Assim, no que se refere à estabilidade em longo prazo os sistemas em pó seco são preferidos.

Os alginatos são polissacarídeos de ocorrência natural. O alginato de sódio é derivado do ácido algínico, polímero linear glicuronano consistindo de uma mistura de resíduos dos ácidos â - (14) - D - manosilurônico e á - (1"4) - L - gulosilurônico arranjados como blocos ao longo da cadeia, onde regiões homopoliméricas estão interdispersas com regiões de estrutura alternantes sem ramificações. De fórmula geral $\left(\mathrm{C}_{6} \mathrm{H}_{8} \mathrm{O}\right)_{n}$, seu peso molecular está tipicamente entre 20000 a 240000 . Este composto é obtido principalmente de algas e uma pequena proporção de grupos carboxílicos pode ser neutralizada (ROWE, SHESKEY e WELLER, 2003).

$\mathrm{O}$ pH é aproximadamente 7,2 para uma solução aquosa a 1\% p/v. Praticamente insolúvel em etanol, éter, clorofórmio e misturas etanol/água com conteúdo de etanol maior que $30 \%$. Também é praticamente insolúvel em outros solventes orgânicos e soluções aquosas acídicas com pH menor do que 3,0. Vagarosamente solúvel na água, forma uma solução coloidal viscosa. A viscosidade varia em função da concentração, $\mathrm{pH}$, temperatura ou presença de íons metálicos. Baixas concentrações de eletrólitos causam um aumento na viscosidade e altas concentrações causam salting-out do alginato de sódio; salting-out ocorre em concentrações de cloreto de sódio superiores a 4\% (ROWE, SHESKEY e WELLER, 2003).

O alginato de sódio é usado em muitas formulações farmacêuticas de uso oral e tópico como também tem sido utilizado na preparação de formulações orais de liberação sustentada por retardar a dissolução de fármacos presentes em comprimidos, cápsulas e suspensões aquosas. Também é agente estabilizador para emulsões o/a. Recentemente tem sido proposto para a microencapsulação aquosa de fármacos em contraste com as técnicas de microencapsulação mais convencionais que utilizam sistemas orgânicos de solventes. Também pode ser utilizado na formação de nanopartículas. A adesividade 
dos hidrogéis de alginato de sódio tem sido estudada, como também a liberação do fármaco a partir de comprimidos adesivos para a mucosa oral (ROWE, SHESKEY e WELLER, 2003).

Eles são capazes de formar géis insolúveis na água por ligação cruzada com cátions divalentes como o $\mathrm{Ca}^{+2}$. Devido ao processo suave de gelificação, um meio aquoso relativamente inerte na matriz e sua alta biocompatibilidade os sistemas hidrogel contendo alginato também têm sido amplamente usados como formador matricial para microencapsulação de peptídeos bioativos, proteínas e também para células vivas (JAN, 2002; SMIDSROD e SKJAK-BRAEK, 1990). Contudo, os géis de alginato degradam e precipitam em tampão fosfato $0,1 \mathrm{M}$ porque os íons cálcio são removidos pela formação de fosfato de cálcio, conduzindo a rápida liberação do fármaco. Além disso, os géis de alginato mostram uma alta porosidade resultando em altos índices de difusão e, por esta razão, têm sido propostos a formação de complexos estáveis de alginato com policátions tais como poli-L-lisina, quitosana ou polietileneimina. Os géis de alginato de cálcio são assim protegidos contra quelantes de $\mathrm{Ca}^{+2}$ e a porosidade das micropartículas é reduzida, resultando em liberação mais sustentada do fármaco (THU et al., 1996). Contudo, é necessário uma etapa de revestimento adicional com o policátion.

A combinação do poloxâmero e de géis de alginato de cálcio em um sistema microparticulado em pó seco mostra-se promissor para superar as restrições dos polímeros individuais. O poloxâmero poderia preencher os poros do gel de alginato e agir como barreira de difusão para os fármacos encapsulados tanto quanto para o meio de dissolução, desta forma reduzindo a troca dos íons cálcio e consequentemente, a degradação do gel de alginato-Ca ${ }^{+2}$ (MOEBUS, SIEPMANN e BODMEIER, 2009).

O objetivo deste estudo é comparar técnicas tradicionais de preparo de micropartículas com o método proposto por MOEBUS, SIEPMANN e BODMEIER (2009), verificar influência de variabilidade de EHL, preparar micropartículas secas de $\mathrm{Ca}^{+2}$-alginato-poloxâmero utilizando o óleo vegetal de amêndoas doce como fase orgânica pelo método de emulsão a/o a frio e com elevação de temperatura $40-45^{\circ} \mathrm{C}$, segundo o proposto pelos autores; investigar a influência da formulação, parâmetros de processamento e lavagem no tamanho e morfologia das micropartículas obtidas por observação em microscopia óptica.

Descrição do método proposto por MOEBUS, SIEPMANN e BODMEIER (2009): as micropartículas foram preparadas por processo de ligação cruzada externa via emulsão a/o. Heptano ou óleo de amendoim foram usados como fase orgânica. (1) Heptano. preparo da solução aquosa contendo os polímeros: preparar vinte gramas de solução aquosa contendo $3 \% \mathrm{p} / \mathrm{p}$ de alginato de sódio e $3 \%$ p/p de poloxâmero 407 ; preparo da solução aquosa de Tween 85 a 25\%: dissolver $25 \mathrm{~g}$ de Tween 85 em água destilada qsp. $100 \mathrm{~g}$ assim, cada grama da solução aquosa de Tween 85 possui $0,25 \mathrm{~g}$ do tensoativo; preparo da solução aquosa de $\mathrm{CaCl}_{2}$ a $25 \%$ p/p: pesar $25 \mathrm{~g}$ de cloreto de cálcio e solubilizar com água destilada qsp. 100g; preparo da fase orgânica: pesar $25 \mathrm{~g}$ de heptano; acrescentar $3,3 \% \mathrm{p} / \mathrm{p}$ de Span 85 (calculado sobre $30 \mathrm{~g}$ de heptano) e completar o peso do heptano qsp. 30g; Processo de emulsificação/obtenção das micropartículas: dispersar a solução polimérica em $30 \mathrm{~g}$ de fase orgânica (índice de volume de a/o de 1:2) usando um agitador magnético a 1000rpm por 10 minutos. Em 
seguida acrescentar $2 \mathrm{~g}$ da solução aquosa de Tween 85 a 25\% (0,5g de Tween 85; resultando em um índice de Span 85:Tween 85 de 2:1). A emulsão foi agitada por mais 5 minutos. O sistema foi aquecido a $40-45^{\circ} \mathrm{C}$ sob agitação contínua sobre um prato de aquecimento magnético. Então, $8 \mathrm{~g}$ de uma solução aquosa de $\mathrm{CaCl}_{2} \quad(25 \% \mathrm{p} / \mathrm{p})$ foi acrescentada em gotas (durante $\sim 4$ minutos) utilizando uma seringa com agulha (Sterican ${ }^{\mathrm{RM}}$ Gr.1 0,90 x 40mm; Braun, Melsungen, Germany). A agitação foi continuada por mais 15 minutos. O sistema foi deixado resfriar por 10 minutos, sob agitação a 200rpm; recuperação das micropartículas: a seguir, as micropartículas foram recuperadas por dois diferentes processos: (i) por filtração a vácuo sem lavagem posterior ou, (ii) por centrifugação, por processos descritos por MOEBUS, SIEPMANN e BODMEIER (2009). (2) Óleo de amendoim: de maneira geral o processo de preparação descrito para (1) heptano foi seguido. Contudo, o processo todo foi conduzido à temperatura ambiente sob agitação com agitador em hélice a 1000rpm (EUROSTAR power controlvisc.;IKA). Dez gramas da solução polimérica aquosa e $20 \mathrm{~g}$ de óleo de amendoim foram usados (índice de volume a/o de 1:2). As micropartículas foram recuperadas por filtração a vácuo. O óleo de amendoim aderido foi removido por lavagem contínua com isopropanol por $3 \times 30 \mathrm{ml}$.

\section{MATERIAL E MÉTODOS}

Alginato de sódio (PROTONAL VK 998), poloxâmero 407 (EMBRAFARMA), Tween 80 (HENRIFARMA), Span 80 (EMFAL), óleo de amêndoas doce (DEG), corante lipofílico vermelho (FAT RED 7B, SIGMA), cloreto de cálcio (Natural Pharma), isopropanol (Farmanilquima), agitador em hélice (FANEM), seringa (INJEX $5 \mathrm{ml}$ ), agulha (KDL 1,20 x 40 mm) e microscópio óptico (STUDAR).

De maneira geral o processo de preparação descrito para (1) heptano e (2) óleo de amendoim proposto por MOEBUS, SIEPMANN e BODMEIER (2009) foram seguidos. O processo todo foi conduzido à temperatura ambiente sob agitação com agitador em hélice a 1000rpm. Dez gramas da solução polimérica aquosa e $20 \mathrm{~g}$ de óleo de amêndoas doce foram usados (índice de volume a/o de 1:2). O óleo de amêndoas doce continha $3,3 \% \mathrm{p} / \mathrm{p}$ de Span $80(0,67 \mathrm{~g})$. O corante lipofílico fat red foi utilizado para corar o óleo de amêndoas doce. As micropartículas foram recuperadas por filtração a vácuo. O óleo de amêndoas doce aderido foi removido por lavagem contínua com isopropanol por 3 $x 30 \mathrm{ml}$. As micropartículas foram gentilmente retiradas com espátula de sobre o papel filtro e colocadas para secar em freezer a $-20^{\circ} \mathrm{C}$ por 48 horas. Após, foram observadas quanto tamanho e morfologia por microscopia óptica. A seguir, repetiu-se exatamente a mesma técnica, porém todo o processo foi conduzido sob aquecimento a $40-45^{\circ} \mathrm{C}$.

\section{RESULTADOS E DISCUSSÃO}

O uso de polímeros formadores de hidrogel representa uma alternativa promissora como materiais para encapsulação. Os alginatos e poloxâmeros incham e gelificam na água retendo uma significante fração de água nas suas estruturas sem dissolver (GOMBOTZ e HOFFMANN 1986). Frequentemente estes hidrogéis são altamente biocompatíveis e normalmente possuem um tempo mais curto de liberação e degradação 
quando comparado, por exemplo, às formulações desenvolvidas com poli-ácido láticoco-ácido glicólico (PLGA). Devido à sua natureza hidrofílica e na maioria das vezes processos suave de preparação, eles propiciam um meio adequado para fármacos peptídicos e protéicos e mostram estabilizar a estrutura complexa destes produtos (ZANIN et al., 2007; PEPPAS et al., 1998; GOMBOTZ e HOFFMANN 1986). Contudo, o controle apropriado da liberação do fármaco desta rede polimérica altamente inchada é um desafio.

O PLGA, o ácido poli-láctico e o ácido poli-glicólico têm sido muito estudados como sistemas carreadores, contudo o tempo de degradação do PLGA, de diversas semanas a meses, não o torna apropriado para todas as vias de administração como, por exemplo, pelas superfícies das vias mucosas. Além disso, o uso de solventes orgânicos durante o microencapsulamento do fármaco nos métodos de extração de solvente em emulsão a/o/a e de evaporação, a hidrofobicidade do polímero e a formação de pequenas regiões acídicas, geradas pela degradação do polímero, frequentemente resultam em uma perda da atividade biológica da proteína. Estes problemas podem ser evitados com o uso de hidrogéis (WEERT, HENNINK e JISKOOT, 2000).

Os métodos de fluidização e de nebulização também utilizam calor e não são apropriados para fármacos termosensíveis. Além disso, o método de nebulização também requer equipamento de custo elevado e é difícil obter partículas esféricas (SILVA, 2003). O método de coacervação, tanto o simples como o complexo, é muito prático de se efetuar em laboratório, contudo normalmente usado para fármacos lipossolúveis (SILVA et al., 2003; ZAMPIERI, LIMA e DINIZ, 2005; MAGILL, 1991).

No presente trabalho as micropartículas de alginato-poloxâmero foram preparadas por emulsão a/o e método de gelificação externo. As gotículas aquosas emulsionadas contendo os polímeros foram transformadas em micropartículas após adição de $\mathrm{CaCl}_{2}$. Os íons cálcio divalentes são ligados de maneira altamente cooperativa às unidades de ácido gulurônico do alginato por ligação cruzada, conduzindo à formação de partículas gelificadas insolúveis na água (MOEBUS, SIEPMANN e BODMEIER, 2009).

Houve variabilidade na distribuição de tamanho das micropartículas para as formulações conduzidas tanto a frio quanto em aquecimento. Maior proporção de aglomerados microparticulados foram observados na formulação desenvolvida a frio, provavelmente devido à menor dispersibilidade das fases da emulsão. Convém observar que em trabalho desenvolvido por MOEBUS, SIEPMANN e BODMEIER (2009) foi possível constatar que o tamanho da partícula não depende da temperatura do sistema emulsionado durante a preparação das micropartículas quando do uso de óleo de amendoim ou outro óleo de origem vegetal como o óleo de amêndoas doce utilizado neste experimento. Consequentemente, pode-se trabalhar sem aquecimento, a temperatura ambiente.

O uso de um agitador em hélice ao invés do agitador magnético tende a dispersar melhor as fases e conduziu a uma significativa diminuição no tamanho das partículas (dados não mostrados).

MOEBUS, SIEPMANN e BODMEIER (2009) trabalharam com os tensoativos Span 85 (trioleato de sorbitano, valor de EHL 1,80) e Tween 85 (trioleato de polioxietilenosorbitano, valor de EHL 11,0) tanto na emulsificação do heptano, como na do óleo de amendoim. Supostamente o baixo EHL do sistema emulsionado mostra-se 
adequado para o heptano, por ser este altamente apolar, e foi extensível ao processo com óleo de amendoim. Este sistema emulsionado favorece a obtenção de emulsão a/o que é o objetivo do método utilizado na obtenção das micropartículas de alginatopoloxâmero. Neste trabalho, contudo, utilizou-se o Span 80 (monoleato de sorbitano, valor de EHL 4,3) e o Tween 80 (monoleato de polioxietilenosorbitano, valor de EHL $15,0)$, subindo ligeiramente o EHL do meio, o que é plausível para óleos de origem vegetal e mantendo o sistema para formação de emulsão a/o.

Nos dois métodos testados as micropartículas foram obtidas, mostrando resultados satisfatórios. No entanto, podemos observar nas Figuras 1 e 2 que o método de obtenção das micropartículas por emulsão a/o a frio resultou em micropartículas de alginato-poloxâmero que apresentaram formato mais irregular, quando comparado ao método de obtenção de micropartículas por emulsão a/o sob aquecimento a 40$45^{\circ} \mathrm{C}$.

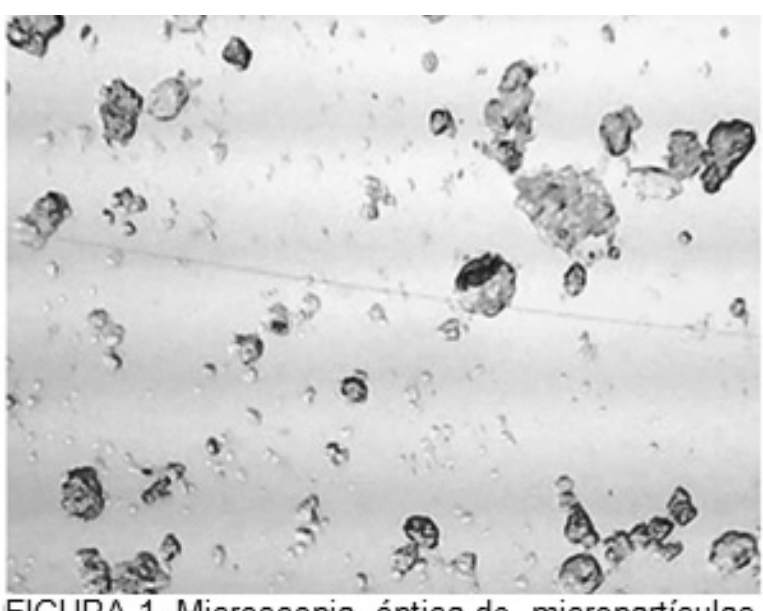

FIGURA 1. Microscopia óptica de micropartículas obtidas por emulsão a/o a frio em aumento de $400 \mathrm{x}$.

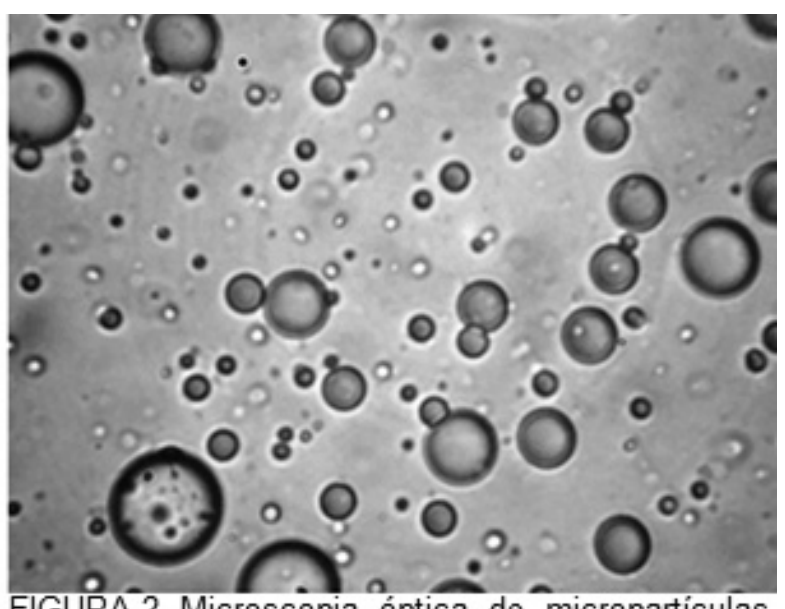

FIGURA 2. Microscopia óptica de micropartículas obtidas por emulsão a/o a $40-45^{\circ} \mathrm{C}$ em aumento de $400 x$.

Durante a lavagem das micropartículas, segundo trabalho de MOEBUS, SIEPMANN E BODMEIER (2009) a filtração a vácuo sem lavagem foi estudada como uma técnica alternativa de recuperação para evitar perda de poloxâmero nas micropartículas preparadas com heptano como fase orgânica, pois sua remoção é quase completa por filtração a vácuo devido à sua baixa viscosidade. O heptano remanescente evapora durante subsequente secagem, pela sua volatilidade. Uma perda significativa de poloxâmero pode ser evitada quando as partículas em ligação cruzada forem filtradas a vácuo e não lavadas. Contudo, com o uso do óleo de amêndoas doce como fase orgânica no preparo da emulsão torna a operação de lavagem inevitável, pois o óleo permanece aderido às micropartículas, como se pode observar na Figura 2.

Verificou-se maior dificuldade em retirar o óleo no sistema preparado a quente, com o mesmo número de lavagens utilizado no sistema a frio. Isto ocorre provavelmente porque na preparação conduzida a $40-45^{\circ} \mathrm{C}$ as fases aquosas e oleosas dispersaramse mais intimamente estabilizando melhor o sistema e dificultando a retirada do óleo por interações físico-químicas mais intensas. 
No presente trabalho observou-se que as micropartículas obtidas pelo método de emulsificação a quente após lavagem por $3 \times 30 \mathrm{ml}$ de isopropanol e posterior armazenamento por $48 \mathrm{~h}$ em freezer a $-20^{\circ} \mathrm{C}$ apresentavam-se como pó grosso, de aparência úmida e cor rosa intensa, sugerindo que o óleo de amêndoas doce não tinha sido retirado de maneira eficaz. Devido a isto se procedeu a mais um processo de lavagem com $30 \mathrm{ml}$ de isopropanol e observou-se ao microscópio óptico as micropartículas dipersas em água, como pode ser visto na Figura 3.

Procedeu-se ainda novas lavagens, com posterior observação em microscopia óptica e como se pode verificar na Figura 4 que mesmo após ter sofrido mais 2 processos de lavagem com isopropanol ainda havia a presença de óleo.

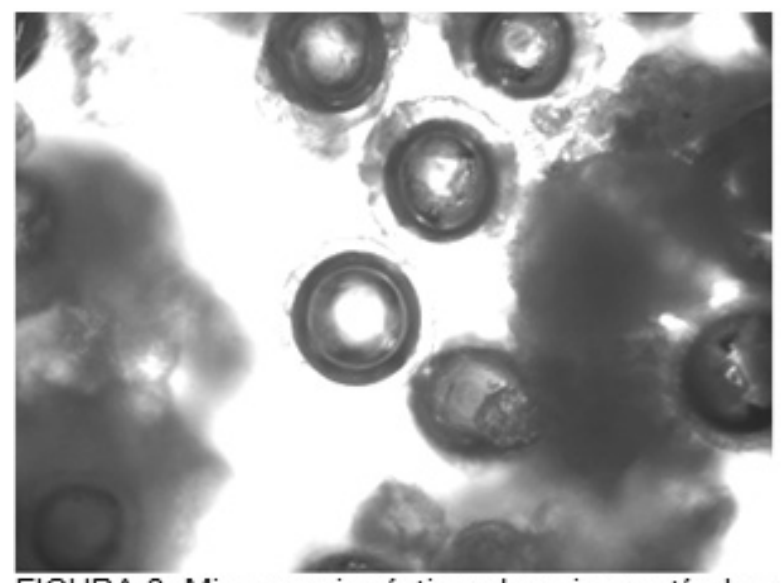

FIGURA 3. Microscopia óptica de micropartículas obtidas por emulsão a/o a $40-45^{\circ} \mathrm{C}$ lavadas 4 vezes com isopropanol em aumento de $400 \mathrm{x}$.

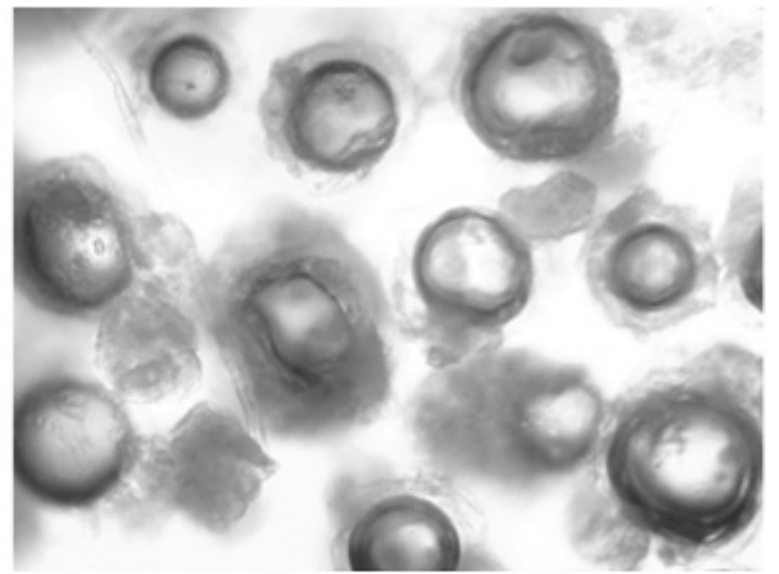

FIGURA 4. Microscopia óptica de micropartículas obtidas por emulsão a/o a $40-45^{\circ} \mathrm{C}$ lavadas 6 vezes com isopropanol em aumento de $400 x$.

No sétimo e último processo de lavagem com $30 \mathrm{ml}$ de isopropanol pode-se observar, Figuras 5 e 6, micropartículas mais livres do óleo, o que foi comprovado pelo pó fino resultante de aparência seca, fluida, e de cor branco-amarelada, indicando que o óleo foi eliminado, pois estava corado de vermelho. Esta cor característica brancoamarelada é a cor natural dos polímeros utilizados.

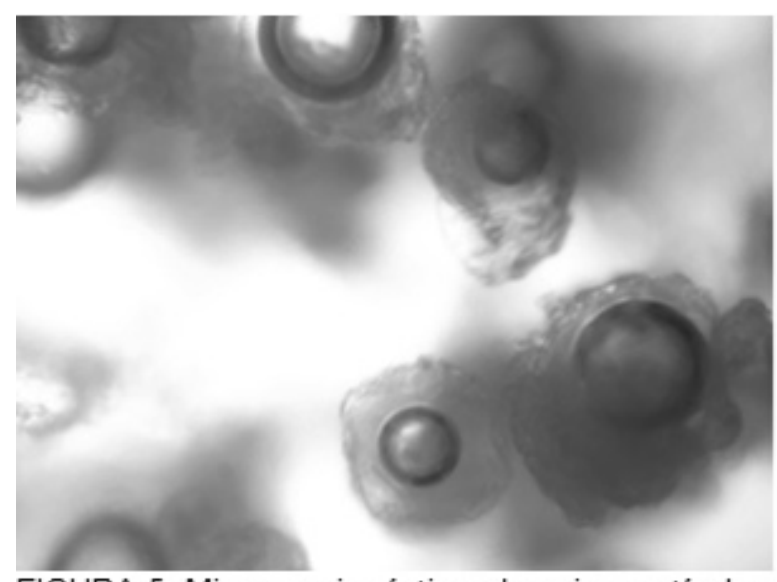

FIGURA 5. Microscopia óptica de micropartículas obtidas por emulsão a/o a $40-45^{\circ} \mathrm{C}$ lavadas 7 vezes com isopropanol em aumento de $400 x$.

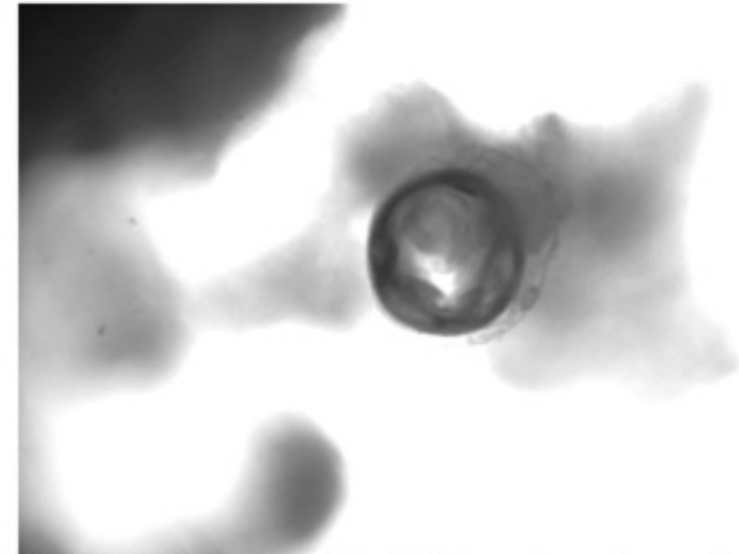

FIGURA 6. Microscopia óptica de micropartícula obtida por emulsão a/o a $40-45^{\circ} \mathrm{C}$ lavada 7 vezes com isopropanol em aumento de $400 \mathrm{x}$. 
O processo de lavagem exaustivo pode ter acarretado perda de poloxâmero pelo fato deste polímero ser solúvel no isopropanol. Esta perda, contudo, depende de quanto polímero está intercalado com o alginato- $\mathrm{Ca}^{+2}$ no sistema. A perda excessiva de poloxâmero por repetitivas lavagens com isopropanol pode acarretar em micropartículas mais frágeis, transparentes e com formato mais distorcido e irregular.

A interação entre os dois polímeros em diversas concentrações e proporções foi estudada e pesquisada por MOEBUS, SIEPMANN e BODMEIER (2009) para a formação de uma rede polimérica com adequada porosidade, durabilidade, forma $\mathrm{e}$ volume visando liberação controlada, chegando à técnica avaliada e modificada a fim de comparação neste trabalho (MOEBUS, SIEPMANN e BODMEIER 2009).

A técnica descrita por MOEBUS, SIEPMANN e BODMEIER (2009) foi elaborada para a obtenção de micropartículas que armazenassem fármacos hidrofílicos termolábeis, principalmente proteínas e polipeptídeos por serem complexos e dificultarem este tipo de procedimento (SILVA et al., 2002b).

Apesar deste trabalho apenas comparar os métodos de obtenção de micropartículas por emulsão a/o a frio e a quente não se descarta a idéia da simplicidade do mesmo para o microencapsulamento de fármacos hidrossolúveis tanto termolábeis quanto termoestáveis, permitindo a utilização de aquecimento para uma melhor emulsificação. Cada método de microencapsulamento tem suas vantagens e desvantagens, portanto a escolha do método deve começar pelo fármaco a ser encapsulado.

\section{REFERÊNCIAS}

AFTABROUCHAD, C.; DOELKER, E. Preparation methods for biodegradable microparticles loaded with water-soluble drugs. STP Pharma Sci., Paris, v. 2, p. 365-380, 1992.

ARSHADY, R. Albumin microspheres and microcapsules: methodology of manufacturing techniques. J. Control Release, Amsterdam, v. 14, p. 111-131, 1990.

ARSHADY, R. Preparation of biodegradable microspheres and microcapsules. Part 2. Polyactides and related polyesters. J. Controlled Release, Amsterdam, v. 17, p. 1-21, 1991.

BAKAN, J. A. Microencapsulation. In: SWARBRICK, J., BOYLAN, J. C., eds. Encyclopedia of Pharmaceutical technology. New York: Marcel Dekker, v. 9., p. 423441, 1994.

BURGESS, D. J.; HICKEY, A. J. Microsphere technology and applications. In: SWARBRICK, J.; BOYLAN, J. C., eds. Encyclopedia of Pharm.aceutical technology. New York: Marcel Dekker, v. 10, p. 1-29, 1994.

DONBROW, M. Introduction and overview. In: DONBROW, M., ed. Microcapsules and nanoparticles in medicine and Pharmacy. Boca Raton: CRC Press, p. 1-14, 1992. 
GIUNCHEDI, P.; CONTE, U. Spray-drying as a preparation method of microparticulate drug delivery systems: overview. STP Pharm.a Sci., Paris, v. 5, p. 276-290, 1995.

GOMBOTZ, W. R.; HOFFMANN, A. S.; Immobilization of biomolecules and cells on and within synthetic polimeric hydrogels, in: N.A. Peppas (Ed.), Hydrogels in Medicine and Pharmacy, CRC Press Boca Raton, p. 95 - 126, 1986.

JAN, T. H. H. K.; Alginate in drug delivery systems, Drug Dev. Ind. Pharm. 28, p. $621-630,2002$.

JEONG, B.; KIM, S. W.; BAE, Y. H.; Thermosensitive sol-gel reversible hydrogels, Adv. Drug delivery Rev. 54, p. $37-51,2002$

KAS, H. S.; ONER, L. Microencapsulation using coacervation / phase separation: an overview of the technique and applications. In: WISE, D. L., ed. Handbook of Pharm.aceutical controlled release technology. New York: Marcel-Dekker, p. 301-328, 2000.

LACHMAN, LEON; LIEBERMAN, HERERT A.;KANIG, JOSEPH L. Third Edition. The Theory and Practice of Industrial Pharmacy. Part Three Microencapsulation. J.A. LEA\&FEBIGER, PHILADELPHIA, p.412 a 428. 902p, 1986.

MAGILL, M. Microencapsulamento. Cosmetics \& Toiletries. Vol.3, Mar/Abr 1991.

MOEBUS, K.; SIEPMANN, J.; BODMEIER, R.; Alginate-poloxamer microparticles for controlled drug delivery to mucosal tissue, European Journal of Pharmaceuticals and Biopharmaceuticals 10.1016, 2009.

PARK, K.; SHALABY, W. S.; PARK, H.; Biodegradable hydrogels for drug delivery, Technomic Publishing, Lancaster, PA, 1993.

PEPPAS, N. A.; BURES, P.; LEOBANDUNG, W.; ICHIKAWA, H. Hydrogels in pharmaceutical formulations. Eur. J. Pharm. Biopharm. 50, p. $27-46,2000$.

ROWE, R. C.; SHESKEY, P. J.; WELLER, P. J. Handbook of pharmaceuticals excipients. Great Britain: Pharmaceutical Press. 4ed. 2003.

SCHMOLKA, J. R.; Artificial Skin 1. Pluronic F-127 gels for treatment of burns, J. Biomed. Master Res 6, p. 571 - 582, 1972.

SILVA, C.; RIBEIRO, A.; FERREIRA, D.; VEIGA, F. Administração oral de peptídios e proteínas: I. Estratégias gerais para aumento da biodisponibilidade oral. Rev. Bras. Cienc. Farm, São Paulo, v. 38, p. 125-140, 2002b.

SILVA, C.; RIBEIRO, A.; FERREIRA, D.; VEIGA, F. Administração oral de peptídios e proteínas: II. Aplicação de métodos de microencapsulação. Rev. Bras. Cienc. Farm, São Paulo, v. 39, n.1, jan./mar., 2003. 
SILVA, C.; RIBEIRO, A.; FERREIRA, D.; VEIGA, F. Administração oral de peptídeos e proteínas: III. Aplicação à insulina. Rev. Bras. Cien. Farm., São Paulo, v. 39, n. 1, p. 21-40, 2003.

SMIDSROD, O; SKJAK-BRAEK, G. Alginate as immobilization matrix for cells. Trends Biotechnology n.8. p.71-78, 1990.

THU, B.; BRUHEIM, P.;ESPEVIK, T.; SMIDSROD, P.; SOON-SHIONG, G.; SKJAKBRAEK, G. Alginate polycation microcapsules. II. Some functional properties. Biomaterials, n.17. p.1069-1079, 1996.

VOS, PAUL; BUCKOL, MAREK; GEMEINER, PETER; NAVRÁTIL, MARIÁN. Multiscale requirements for bioencapsulation in medicine and biotechnology. Elsevier Science LTD. Biomaterials 30, 2009.

WAN, L. S.; HENG, P. W.; CHAN, L. W. Drug encapsulation in alginate microspheres by emulsification. J. Microencapsul., London, v. 9, p. 309-316, 1992.

WEERT, M. VAN DE; HENNINK, W. E.; JISKOOT, W. Protein stability in poly (lacticco-glycolic acid) microparticles. Pharm. Res. 17, p. 1159 - 1167, 2000.

ZAMPIERI, A. L.; LIMA, E. M.; DINIZ, D. G.; Estudo da ligação cruzada induzida pelo formaldeído em cásulas de gelatina dura. Revista eletrônica de farmácia Vol.2 (2), 73-79. 2005.

ZANIN, S. M. W.; MIGUEL, M. D.; BARREIRA, S. M. W.; NAKASHIMA, T.; CURY, C. D.; COSTA,C. K. Enxaguatório bucal: principais ativos e desenvolvimento de fórmula contendo extrato hidroalcoólico de Salvia officinalis. Visão Acadêmica, vol. 8, jan./jun. 2007. 